\title{
\begin{tabular}{l|l} 
Mitraries & DSpace@MIT
\end{tabular}
}

\author{
MIT Open Access Articles
}

Water-Soluble Cationic Conjugated Polymers:
Response to Electron-Rich Bioanalytes

The MIT Faculty has made this article openly available. Please share how this access benefits you. Your story matters.

Citation: Rochat, Sebastien, and Timothy M. Swager. “Water-Soluble Cationic Conjugated Polymers: Response to Electron-Rich Bioanalytes." Journal of the American Chemical Society 135, no. 47 (November 27, 2013): 17703-17706.

As Published: http://dx.doi.org/10.1021/ja4095395

Publisher: American Chemical Society (ACS)

Persistent URL: http://hdl.handle.net/1721.1/84619

Version: Author's final manuscript: final author's manuscript post peer review, without publisher's formatting or copy editing

Terms of Use: Article is made available in accordance with the publisher's policy and may be subject to US copyright law. Please refer to the publisher's site for terms of use. 
This document is confidential and is proprietary to the American Chemical Society and its authors. Do not copy or disclose without written permission. If you have received this item in error, notify the sender and delete all copies.

\section{Water-Soluble Cationic Conjugated Polymers: Response to Electron-Rich Bioanalytes}

\begin{tabular}{|r|l|}
\hline Journal: & Journal of the American Chemical Society \\
\hline Manuscript ID: & ja-2013-095395.R1 \\
\hline Manuscript Type: & Communication \\
\hline Complete List of Authors: & $\begin{array}{l}\text { Rochat, Sébastien; Massachusetts Institute of Technology, Department of } \\
\text { Chemistry 18-597 } \\
\text { Swager, Timothy; Mass. Inst. of Tech., Chemistry; Massachusetts Institute } \\
\text { of Technology, Department of Chemistry 18-597 }\end{array}$ \\
\hline
\end{tabular}

\section{SCHOLARONE ${ }^{\text {ix }}$}

Manuscripts 
Conjugated polymer semiconductors have advantageous properties (flexibility, low weight, good processability in solution) that make them useful for optoelectronic and electrochemical devices including organic solar cells, ${ }^{1-8}$ light-emitting diodes, ${ }^{9}$ field-effect transistors, $10-13$ chemo- ${ }^{14-15}$ and biosensors. ${ }^{16}$ In contrast to $\mathrm{p}$ type conjugated polymers, which are currently the leading class of organic semiconductors, ${ }^{17-19}$ n-type (or electron-transporting) conjugated polymers are still in limited supply $y^{20-26}$ and are often hampered by lower performance and stability. This lack of suitable n-type polymeric materials has hindered progress in all polymer organic electronics, and research in polymer photovoltaic devices is largely focused on fullerene-based acceptor molecules, ${ }^{5,7}$ in spite of the poor visible light absorption and bandedge variability of such compounds. ${ }^{27}$ In addition to the widespread organic electronics applications, conjugated polymers have been extensively studied for chemical and biological sensing, ${ }^{28-29}$ such as the detection of vapors, ${ }^{30-32}$ anions, ${ }^{33}$ or biomolecules. ${ }^{34-36}$ Of particular relevance to the present study are the solution-based optical detection schemes for electron-rich bioanalytes. ${ }^{35-36}$

The incorporation of electron-deficient N-heterocyclic aromatics into conjugated polymers to produce $\mathrm{n}$-type compounds with high electron affinities was successfully employed in our laboratory $^{37}$ and by others. ${ }^{24-25}$ We recently reported a new class of $n-$ type conjugated polymers based on a pyridinium-phenylene scaffold, that possess reversible redox activities, useful electron affinities, and high electrical conductivities. In these compounds, electron-deficient pyridinium rings were introduced by intramolecular cyclization reactions. ${ }^{37 \mathrm{c}}$

Building on this success, we now introduce a related class of poly(pyridinium phenylene)s, which are more synthetically accessible, thereby facilitating the development of electrochemical and photophysical applications. Further, we demonstrate that these electron-deficient polymers are sensitive to electron-rich analytes

and display fluorescence responses to analytes of biological and physiological interest. In particular, an aqueous solution of one of the reported polymers is able differentiate indole among a series of biologically relevant analytes, and to measure caffeine concentrations down to $25 \mu \mathrm{M}$.

Our simplified synthetic scheme conveniently generates monomeric unit 3 with minimial synthetic and purification steps (Scheme 1). The synthesis involves Sonogashira coupling of 5bromo-2-iodopyridine with propargyl ether to afford precursor 1 in good yield. In the presence of Wilkinson's catalyst $\left(\mathrm{RhCl}\left(\mathrm{PPh}_{3}\right)_{3}\right)$ and excess of protected hex-3-yne-1,6-diol (2), diyne 1 undergoes $[2+2+2]$ cycloaddition to afford symmetrical monomer 3 . The low yield of this optimized cyclization reaction is mostly attributed to interactions between the metal catalyst and the pyridine rings, and is largely compensated by the simplicity of the synthesis. ${ }^{38}$ Furthermore, most of the unreacted alkyne 2 can be recycled.

Scheme 1. Two-step synthesis of monomer 3

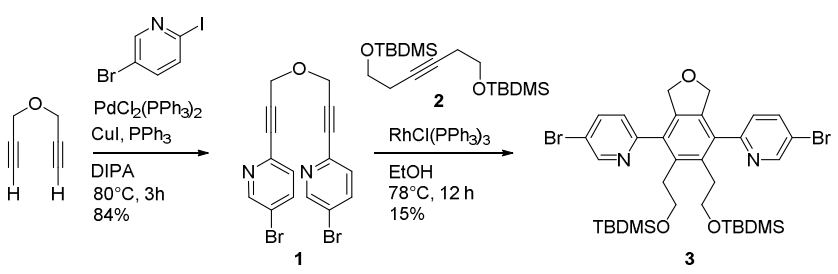

Siloxyethyl-substituted homopolymer P1 and copolymer P2 were obtained reacting monomer $\mathbf{3}$ under Yamamoto and Sonogashira coupling conditions, respectively (Scheme 2). In the case of P1, we observed that microwave irradiation combined with high temperature heating in THF was required in order to enhance the molecular weight of the product. This observation is attributed to an improved solubility of P1 in hot THF. Similarly, we observed no formation of Sonogashira-coupling product when monomer $\mathbf{3}$ and pentiptycene diacetylene $\mathbf{4}$ were reacted under standard (e.g., overnight heating to reflux) conditions. It appears that the lower reactivity of the aryl bromide 3 under Sonogashira conditions, although advantageous for the selective synthesis of precursor 1, is significantly enhanced by the use of superheated solvent in a sealed vessel microwave reactor. Polymers P1 and P2 were found to be soluble in common organic solvents, allowing their convenient purification and characterization. Finally, polyelectrolytes P3 and P4 were obtained by subjecting precursors to intramolecular nucleophilic substitution reactions, and purified by reprecipitation from $\mathrm{H}_{2} \mathrm{O} / \mathrm{THF}(\mathbf{P 3})$ or $\mathrm{DMSO} / \mathrm{H}_{2} \mathrm{O}$ followed by washing with $\mathrm{H}_{2} \mathrm{O}, \mathrm{MeOH}$ and $\mathrm{CH}_{2} \mathrm{Cl}_{2}$ (P4). Homopolymer $\mathbf{P 3}$ 
was found to be soluble in water and trifluoroethanol, whereas copolymer $\mathbf{P 4}$ was found to only display significant solubility in DMSO or in formic acid. Meta-stable aqueous solutions of P4 could be prepared by dissolving the polymer in formic acid followed by dilution with water, and these formulations were stable for several hours before precipitation became visible.

Scheme 2. Synthetic routes to polymers P3 and P4.

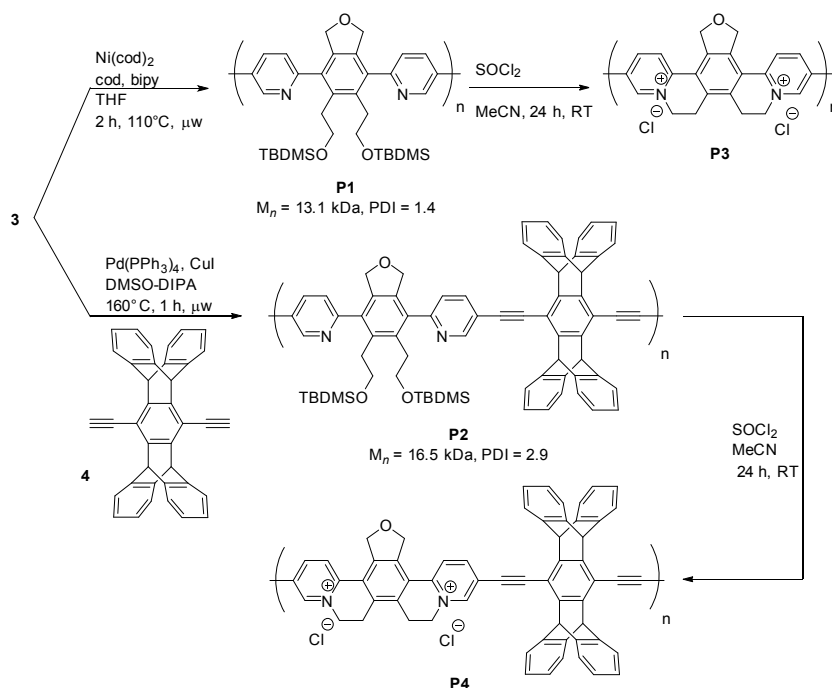

The polycationic polymers $\mathbf{P 3}$ and $\mathbf{P 4}$ were characterized by ${ }^{1} \mathrm{H}$ NMR spectroscopy, absorbance and fluorescence measurements, and by cyclic voltammetry. The optical and electrochemical properties are summarized in Table 1. The absorbance and emission bands of $\mathbf{P 3}$ and $\mathbf{P 4}$ are red shifted relative to the precursor polymers $\mathbf{P 1}$ and $\mathbf{P 2}$, as a result of the enhanced planarity induced by cyclization, and of the incorporation of electron accepting pyridiniums (Figures 1a and b, S7 and S8). The pentiptycene fragment of $\mathbf{P 4}$ induces broader absorbance and emission bands, a larger Stokes shift, and red-shifted bands compared to P3. The electron affinities (EA) of P3 and P4 are evaluated based on the onset reduction potential in thin film cyclic voltammetry measurements, ${ }^{39}$ and are estimated at 3.95 and $3.91 \mathrm{eV}$, respectively. These values are comparable to those of well-known electron transporters PCBM $(4.2 \mathrm{eV})^{7}$ and polybenzimidazobenzophenanthroline $(\mathrm{BBL}, 4.0 \mathrm{eV}){ }^{40}$ The conductivity of a film of polymer P3 was estimated with in situ measurement carried out on interdigitated microelectrodes (Figure 1c). ${ }^{41-42}$ Inherent nonuniformity in the film limits the accuracy of this method, however these measurements clearly reveal that conductivity appears with reduction of the polymer. Significant conductivity was recorded at moderately reducing potentials $\left(1.7 \mathrm{~S} \mathrm{~cm}^{-1}\right.$ at $-1.36 \mathrm{~V} v s$. SCE), and the fully reduced (neutral) polymer was found to be insulating. ${ }^{43}$ Spectroelectrochemical measurements of polymer thin films deposited on ITO-coated electrodes (Figures 1d and S11) revealed that upon reduction of the polymers, the bandgap absorbance significantly decreases, and new mid-gap energy states appear, which is in agreement with our conductivity measurements and the polaron-bipolaron theory for conjugated polymer doping. ${ }^{37 \mathrm{c}, 44-}$ ${ }^{45}$ This effect is less pronounced for polymer $\mathbf{P 4}$ where the redoxactive groups may be effectively isolated by the interveining nonredox active repeating unit.
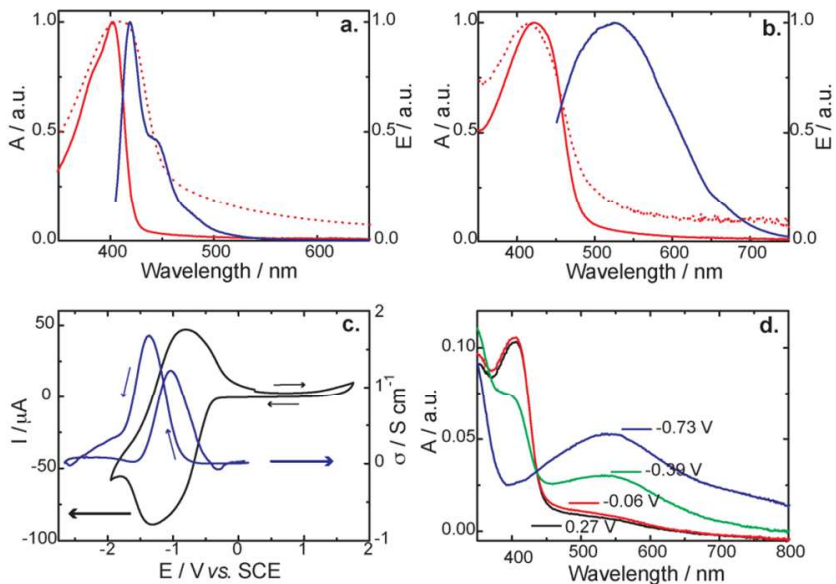

Figure 1. a) Normalized absorbance (red) and emission (blue) spectra of polymer P3 in aqueous solution (solid line) and thin film (dotted line); b) Normalized absorbance (red) and emission (blue) spectra of polymer $\mathbf{P 4}$ in formic acid/PBS (5-95) solution (solid line) and thin film (dotted line); c) Cyclic voltammogram of P3 (black curve, $100 \mathrm{mV} \cdot \mathrm{s}^{-1}$ ) and in situ conductivity measuremnt (blue curve, $5 \mathrm{mV} \cdot \mathrm{s}^{-1}$ ). The deviations below zero are the result of overlapping current from Faradaic processes; d) Spectroelectrochemistry of $\mathbf{P 3}$ (thin film).

Table 1. Optical and electrochemical properties of $\mathbf{P 3}$ and $\mathbf{P 4}$ in solution (s) or thin films (f).

\begin{tabular}{lccccccccc}
\hline & $\begin{array}{c}\lambda_{\max } \\
(\mathrm{nm})\end{array}$ & $\begin{array}{c}\varepsilon_{\max }\left(\mathrm{L}^{-1}\right. \\
\left.\mathrm{mol}^{-1}\right)\end{array}$ & $\begin{array}{c}\lambda_{\text {onset }} \\
(\mathrm{nm})\end{array}$ & $\begin{array}{c}E_{\mathrm{g}}{ }^{a} \\
(\mathrm{eV})\end{array}$ & $\begin{array}{c}E_{\text {red }}{ }^{b} \\
(\mathrm{~V})\end{array}$ & $\begin{array}{c}E_{\text {onset }}{ }^{b} \\
(\mathrm{~V})\end{array}$ & $\begin{array}{c}\mathrm{EA}^{c} \\
(\mathrm{eV})\end{array}$ & $\begin{array}{c}\mathrm{IP}^{d} \\
(\mathrm{eV})\end{array}$ & $\begin{array}{c}\mathrm{PL}_{\max } \\
(\mathrm{nm})\end{array}$ \\
\hline P3 (s) & 402 & 33000 & 421 & 2.95 & & & & 419 \\
P3 (f) & 411 & & 451 & 2.75 & -0.68 & -0.45 & 3.95 & 6.70 & 445 \\
P4 (s) & 423 & 11500 & 478 & 2.60 & & & & & 522 \\
P4 (fi) & 413 & & 494 & 2.51 & -0.85 & -0.49 & 3.91 & 6.42 & 556
\end{tabular}

${ }^{a} E_{\mathrm{g}}$ : Band gap estimated from the onset $\left(\lambda_{\text {onset }}\right)$ of the absorption spectra. ${ }^{b} E_{\text {red }}, E_{\text {onset }}$ : Formal and onset reduction potentials (vs. SCE). ${ }^{c}$ EA: Electron affinity obtained based on EA $=E_{\text {onset }}+$ $4.4(\mathrm{eV}) .{ }^{d} \mathrm{IP}$ : Ionization potential calculated from $\mathrm{IP}=\mathrm{EA}+E_{\mathrm{g}}$ $(\mathrm{eV}) .{ }^{39}$

Taking advantage of the polycationic nature of polymers P3 and $\mathbf{P 4}$, we investigated the possibility of forming well defined films using the layer-by-layer deposition (LbL) technique ${ }^{46}$ in association with anionic poly(styrene sulfonate) (PSS). The absorbance spectra shown in Figure 2a and S12-S13 demonstrate that LbL films are efficiently formed upon alternate exposure of an ITO-coated glass substrate to aqueous solutions of P3 (or P4) and PSS. The absorbance was found to increase linearly with the number of deposited layers, indicating a well-behaved deposition process. Cyclic voltammetry performed on LbL-deposited films ( 25 bilayers) indicates that the multilayer films remain stable during redox changes. As expected, the peak currents were found to increase linearly with the scan rates (Figure 2b, S14-S15). Spectroelectrochemical experiments reveal electrochromism similar to that observed with polymer thin films, with a significantly improved reversibility in the case of $\mathbf{P 3}$ (Figure 2d). Following application of a sufficiently reducing potential, the initially orange film turns blue due to the reduction of P3. The initial color is recovered upon reoxidization, and the color changes occur within about $5 \mathrm{~s}$. 

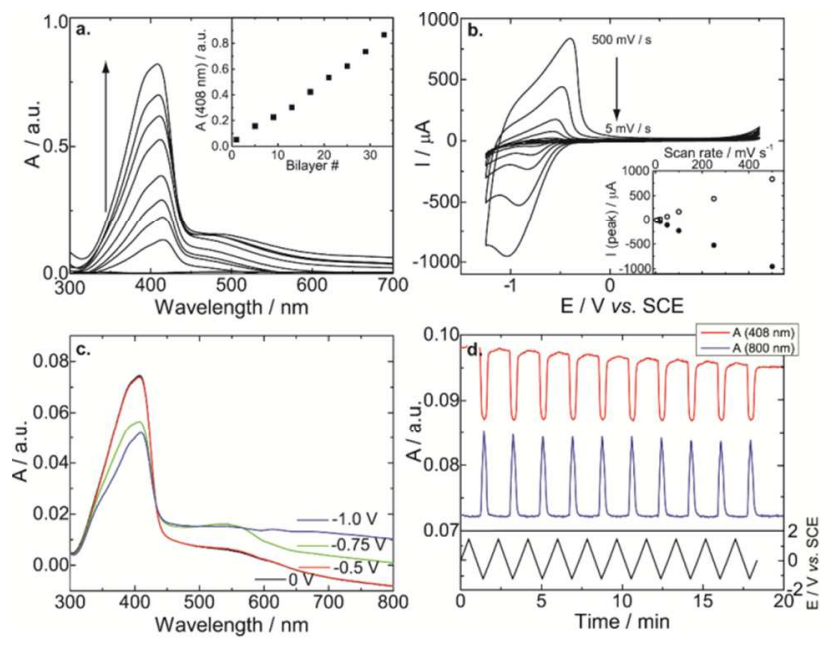

Figure 2. a) Absorbance spectra of $\mathbf{P 3} / \mathrm{PSS}$ films with increasing numbers of bilayers; b) Cyclic voltammograms of a 25-bilayer film of P3/PSS at different scan rates (inset: peak currents for oxidation (open circles) and reduction (filled circles) vs. scan rate); c) Spectroelectrochemistry of a 25 bilayer film of P3/PSS; d) Absorbance changes at 408 (red) and $800 \mathrm{~nm}$ (blue) of a P3/PSS film upon ramping the voltage between 1.5 and $-1.25 \mathrm{~V}$ at a $50 \mathrm{mV} \cdot \mathrm{s}^{-1}$ rate (black).

To evaluate its utility as a sensory material, we investigated the response of copolymer $\mathbf{P 4}$ to a series of analytes of biological interest. Although $\mathbf{P 4}$ is relatively weakly emissive in solution, its high ionization potential (and associated high excited-state electron affinity) is particularly well-suited to interact with electronrich analytes. Indeed solutions of $\mathbf{P} 4$ in water $\left(15 \mu \mathrm{g} \mathrm{mL} L^{-1}\right.$, formate buffer, $\mathrm{pH}$ 3.6) give responses to $100 \mu \mathrm{M}$ of electrondonating aromatic analytes (Figure 3a). The majority of the heterocycles give an enhancement in the emission, however indole induces a $48 \%$ decrease in the fluorescence intensity. This quenching is consistent with our previous work on high ionization potential conjugated polymers and was rationalized by electrontransfer quenching from the electron-donating analyte to the polymer. ${ }^{35-36}$ In order to gain more insight into the quenching mechanism, we performed Stern-Volmer quenching experiments, observing both the emission intensity and lifetime as a function of the indole concentration. The linear increase in quenching with the concentration of indole illustrated in Figure $3 \mathrm{~b}$ reveals a SternVolmer constant $K_{\mathrm{SV}}=9.5(0.6) \cdot 10^{3} \mathrm{M}^{-1}$ and an estimated detection limit of $25 \mu \mathrm{M}$. The fluorescence lifetime $(\tau=0.4 \mathrm{~ns})$ was found to be invariant as indole was added to the solution, pointing towards a static quenching mechanism. The fact that the other investigated analytes produced an increase in the emission intensity admittedly was unexpected and suggests a more complex interaction mechanism between the analytes and the polymer. Copolymer $\mathbf{P 4}$ has large hydrophobic surfaces and we assume that intraand intermolecular hydrophobic interactions have a strong impact on the polymer structure in solution, that can be influenced by the presence of interacting aromatic molecules. For example, although phenylalanine does not possess an easily oxidizable aromatic ring, it still induces a strong fluorescence increase. Further, the importance of the hydrophobic iptycenes in the sensing process is confirmed by the fact that homopolymer P3 shows no significant optical response in the presence of the tested analytes. Nevertheless, the fact that indole responds differently than any other studied analyte (including closely-related tryptophan, that induces an $11 \%$ increase in fluorescence intensity) potentially provides a powerful level of selectivity, where a single specific analyte is detected against several others.
The second analyte of particular interest was caffeine. In the presence of $100 \mu \mathrm{M}$ of caffeine, the fluorescence intensity of the polymer solution increased by $38 \%$, the largest measured increase over our panel of analytes. A titration study performed with various concentrations of caffeine allowed to estimate a detection limit of $25 \mu \mathrm{M}$ (Figures 3c and S17), which makes our sensing scheme competitive with formerly reported schemes for the solution-based optical sensing of caffeine ${ }^{47-49}$ In particular, a detection limit of $50 \mu \mathrm{M}$ was recently reported using polysulfonated pyrenes as molecular probes. ${ }^{47}$

We were able to use $\mathbf{P} \mathbf{4}$ to estimate the caffeine content of a series of everyday products. In this procedure, the selected samples were extracted (coffee and decaffeinated coffee, soda, energy drink, and a painkiller) into dichloromethane and evaporated, in order to minimize the influence of the matrix. The extracts were then redissolved in formate buffer and added into aqueous solutions of polymer P4. The change in fluorescence intensity was measured, and the caffeine content in the samples was then calculated using the calibration curve displayed in Figure 3c. This procedure yielded caffeine concentrations within a reasonable margin of error for most samples, but coffee and decaffeinated coffee displayed erroneously high values (Figure 4). These discrepancies may be the result of additional analytes present in the beverages that interfere in a non-selective fashion with $\mathbf{P 4}$ and contribute to the fluorescence increase.
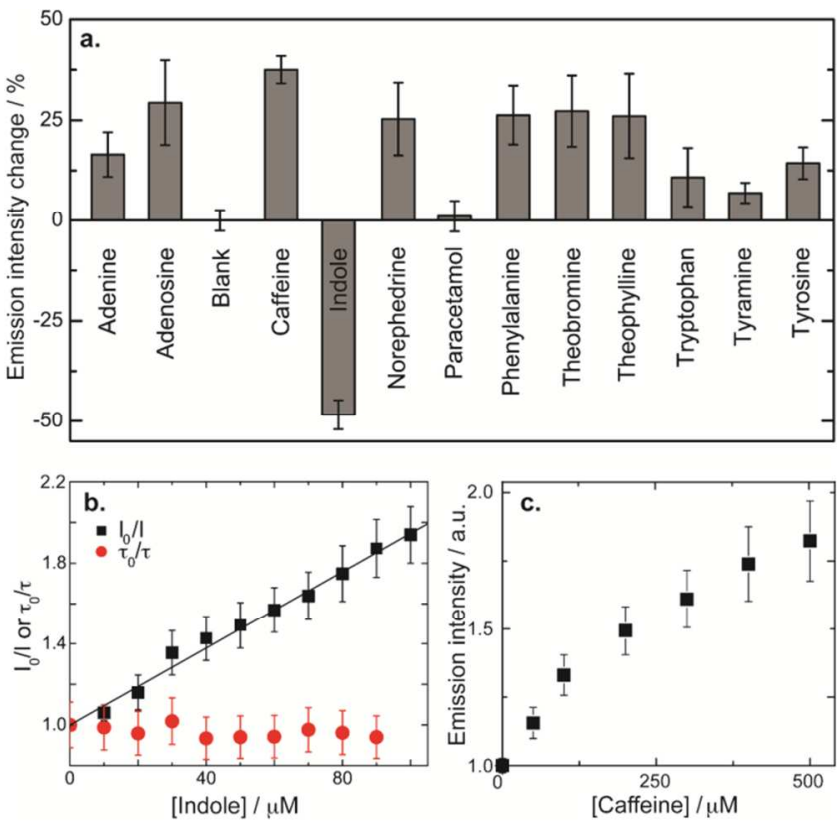

Figure 3. a) Fluorescence intensity changes of solutions of $\mathbf{P 4}$ in water (formate buffer, $\mathrm{pH}$ 3.6) in the presence of electrondonating bioanalytes $\left(100 \mu \mathrm{M}\right.$ concentrations, $\lambda_{\mathrm{ex}}=406 \mathrm{~nm}, \lambda_{\mathrm{em}}=$ $536 \mathrm{~nm}$ ); b) Stern-Volmer plots displaying fluorescence intensity and lifetime of $\mathbf{P 4}$ as a function of indole concentration. The line corresponds to a linear fit with $K_{\mathrm{SV}}=9.5(0.6) \cdot 10^{3} \mathrm{M}^{-1}$; c) Emission intensity changes upon titration of $\mathbf{P 4}$ with caffeine under the same conditions. All displayed data are averages of three independent measurements. 


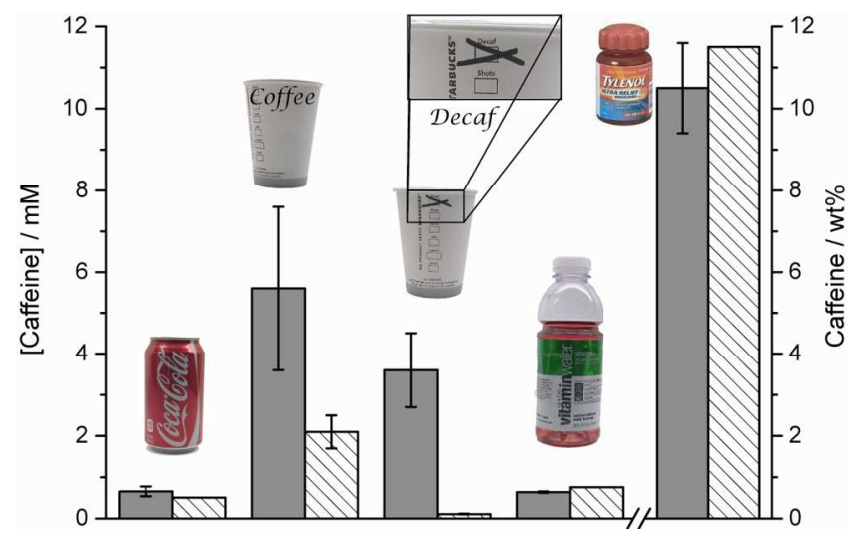

Figure 4. Caffeine content of four liquid and one solid sample, as determined by our assay (grey) or as reported on the containers (striped). All data represent the average of three independant measurements, and the expected values for the coffee samples were taken from ref. 50 .

In summary, we have described a simple synthetic pathway and characterization of cationic conjugated polymers that possess interesting optical and electrochemical properties. These materials have high electron affinities, useful ionization potentials and large Stokes shift (in particular in the case of the iptycene containing copolymer P4). They can be conveniently processed using simple layer-by-layer methodologies, and we also demonstrated that such polymers can act as optical probes for various analytes of biological interest in aqueous solutions, such as indole and caffeine. Further studies to elucidate the interaction mechanisms behind the fluorescence responses are required in order to fine-tune the sensing abilities of these compounds.

\section{ASSOCIATED CONTENT}

\section{Supporting Information}

Synthesis, characterization and properties of the investigated compounds, and structures of the tested bioanalytes. This material is available free of charge via the Internet at http://pubs.acs.org.

\section{AUTHOR INFORMATION}

\section{Corresponding Author}

tswager@mit.edu

Notes

The authors declare no competing financial interests.

\section{ACKNOWLEDGMENT}

This work was supported by the Swiss National Science Foundation (fellowships PBELP2-135845 and PA00P2-145389) and the Army Research Office through the Institute for Soldier Nanotechnologies.

\section{REFERENCES}

(1) Beaujuge, P. M.; Fréchet, J. M. J. J. Am. Chem. Soc. 2011, 133, 20009. (2) Popere, B. C.; Della Pelle, A. M.; Poe, A.; Thayumanavan, S. Phys. Chem. Chem. Phys. 2012, 14, 4043.

(3) Zhou, H.; Yang, L.; You, W. Macromolecules 2012, 45, 607.

(4) Zhan, X.; Zhu, D. Polym. Chem. 2010, 1, 409

(5) Brabec, C. J.; Gowrisanker, S.; Halls, J. J. M.; Laird, D.; Jia, S.; Williams, S. P. Adv. Mat. 2010, 22, 3839.

(6) Peet, J.; Heeger, A. J.; Bazan, G. C. Acc. Chem. Res. 2009, 42, 1700. (7) Thompson, B. C.; Fréchet, J. M. J. Angew. Chem., Int. Ed. 2008, 47, 58.

(8) Günes, S.; Neugebauer, H.; Sariciftci, N. S. Chem. Rev. 2007, 107, 1324.
(9) Grimsdale, A. C.; Chan, K. L.; Martin, R. E.; Jokisz, P. G.; Holmes, A. B. Chem. Rev. 2009, 109, 897.

(10) Wang, C.; Dong, H.; Hu, W.; Liu, Y.; Zhu, D. Chem. Rev. 2012, 112, 2208

(11) Operamolla, A.; Farinola, G. M. Eur. J. Org. Chem. 2011, 423.

(12) Allard, S.; Forster, M.; Souharce, B.; Thiem, H.; Scherf, U. Angew. Chem., Int. Ed. 2008, 47, 4070 .

(13) Murphy, A. R.; Fréchet, J. M. J. Chem. Rev. 2007, 107, 1066.

(14) Fan, L.-J.; Zhang, Y.; Murphy, C. B.; Angell, S. E.; Parker, M. F. L.; Flynn, B. R.; Jones Jr, W. E. Coord. Chem. Rev. 2009, 253, 410.

(15) Swager, T. M. Acc. Chem. Res. 1998, 31, 201.

(16) Feng, X.; Liu, L.; Wang, S.; Zhu, D. Chem. Soc. Rev. 2010, 39, 2411.

(17) McCulloch, I.; Heeney, M.; Bailey, C.; Genevicius, K.; MacDonald, I.; Shkunov, M.; Sparrowe, D.; Tierney, S.; Wagner, R.; Zhang, W.; Chabinyc, M. L.; Kline, R. J.; McGehee, M. D.; Toney, M. F. Nat. Mater. 2006, 5,328 .

(18) Usta, H.; Lu, G.; Facchetti, A.; Marks, T. J. J. Am. Chem. Soc. 2006, 128,9034 .

(19) McCullough, R. D. Adv. Mat. 1998, 10, 93.

(20) Takeda, Y.; Andrew, T. L.; Lobez, J. M.; Mork, A. J.; Swager, T. M. Angew. Chem., Int. Ed. 2012, 51, 9042.

(21) Usta, H.; Facchetti, A.; Marks, T. J. Acc. Chem. Res. 2011, 44, 501.

(22) Zhao, X.; Zhan, X. Chem. Soc. Rev. 2011, 40, 3728.

(23) Yan, H.; Chen, Z.; Zheng, Y.; Newman, C.; Quinn, J. R.; Dötz, F.; Kastler, M.; Facchetti, A. Nature 2009, 457, 679.

(24) Kulkarni, A. P.; Tonzola, C. J.; Babel, A.; Jenekhe, S. A. Chem. Mater. 2004, 16, 4556.

(25) Babel, A.; Jenekhe, S. A. J. Am. Chem. Soc. 2003, 125, 13656.

(26) Guo, X.; Kim, F. S; Seger, M. J.; Jenekhe, S. A.; Watson, M. D. Chem. Mater. 2012, 24, 1434.

(27) Chirvase, D.; Parisi, J.; Hummelen, J. C.; Dyakonov, V. Nanotechnology 2004, 15, 1317.

(28) Thomas, S. W.; Joly, G. D.; Swager, T. M. Chem. Rev. 2007, 107, 1339.

(29) Rochat, S.; Swager, T. M. ACS Appl. Mater. Interfaces. 2013, 5, 4488.

(30) Cox, J. R.; Müller, P.; Swager, T. M. J. Am. Chem. Soc. 2011, 133, 12910 .

(31) Esser, B.; Swager, T. M. Angew. Chem., Int. Ed. 2010, 49, 8872.

(32) Yang, J.-S.; Swager, T. M. J. Am. Chem. Soc. 1998, 120, 11864.

(33) Kim, T.-H.; Swager, T. M. Angew. Chem., Int. Ed. 2003, $42,4803$.

(34) Cordovilla, C.; Swager, T. M. J. Am. Chem. Soc. 2012, 134, 6932.

(35) Kim, Y.; Swager, T. M. Macromolecules 2006, 39, 5177.

(36) Kim, Y.; Whitten, J. E.; Swager, T. M. J. Am. Chem. Soc. 2005, 127, 12122.

(37) (a) Marsella, M. J.; Fu, D.-K.; Swager, T. M. Adv. Mater. 1995, 7, 145; (b) Fu, D.-K.; Xu, B.; Swager, T. M. Tetrahedron 1997, 53, 15487; (c) Izuhara, D.; Swager, T. M. J. Am. Chem. Soc. 2009, 131, 17724.

(38) A series of other catalysts commonly employed for this type of reaction was screened (e.g., $[\operatorname{Ir}(\operatorname{cod}) \mathrm{Cl}]_{2}, \mathrm{CpRu}\left(\mathrm{PPh}_{3}\right)_{2} \mathrm{Cl},[\mathrm{Rh}(\operatorname{cod}) \mathrm{Cl}]_{2}$, $\mathrm{RhCl}_{3}, \quad \mathrm{Co}_{2}(\mathrm{CO})_{8}, \mathrm{CoCl}_{2}, \mathrm{CpCo}(\mathrm{CO})_{2}, \quad$ or $\mathrm{Cp}_{2} \mathrm{ZrCl}_{2}$ under various conditions), and only Wilkinson's catalyst was found to afford the desired product in significant amount.

(39) Li, Y.; Ding, J.; Day, M.; Tao, Y.; Lu, J.; D'Iorio, M. Chem. Mater 2004, 16, 2165 .

(40) Alam, M. M.; Jenekhe, S. A. Chem. Mater. 2004, 16, 4647.

(41) Kittlesen, G. P.; White, H. S.; Wrighton, M. S. J. Am. Chem. Soc. 1984, 106, 7389

(42) Nishizawa, M.; Ise, T.; Koshika, H.; Itoh, T.; Uchida, I. Chem. Mater. 2000, 12, 1367.

(43) Difficulties in processing polymer $\mathbf{P 4}$ made it impossible to reliably determine conductivity by in situ measurements.

(44) Brédas, J. L.; Street, G. B. Acc. Chem. Res. 1985, 18, 309.

(45) Heeger, A. J.; Kivelson, S.; Schrieffer, J. R.; Su, W.-P. Rev. Mod. Phys. 1988, 60, 781.

(46) Decher, G. Science 1997, 277, 1232

(47) Rochat, S.; Steinmann, S. N.; Corminboeuf, C.; Severin, K. Chem. Commun. 2011, 47, 10584.

(48) Luisier, N.; Ruggi, A.; Steinmann, S. N.; Favre, L.; Gaeng, N.; Corminboeuf, C.; Severin, K. Org. Biomol. Chem. 2012, 10, 7487.

(49) Mahapatra, A. K.; Roy, J.; Sahoo, P.; Mukhopadhyay, S. K.; Mukhopadhyay, A. R.; Mandal, D. Bioorg. Med. Chem. Lett. 2012, 22, 5379. 
(50) a) McCusker, R. R.; Goldberger, B. A.; Cone, E. J. J. Anal. Toxicol. 2003, 27, 520. b) McCusker, R. R.; Fuehrlein, B.; Goldberger, B. A.;

Gold, M. S.; Cone,

E. J. J. Anal. Toxicol. 2006, 30, 611.

1

2

3

4

5

6

7

8

9

10

11

12

13

14

15

16

17

18

19

20

21

22

23

24

25

26

27

28

29

30

31

32

33

34

35

36

37

38

39

40

41

42

43

44

45

46

47

48

49

50

51

52

53

54

55

56

57

58

59

60

\section{TOC Graphic}

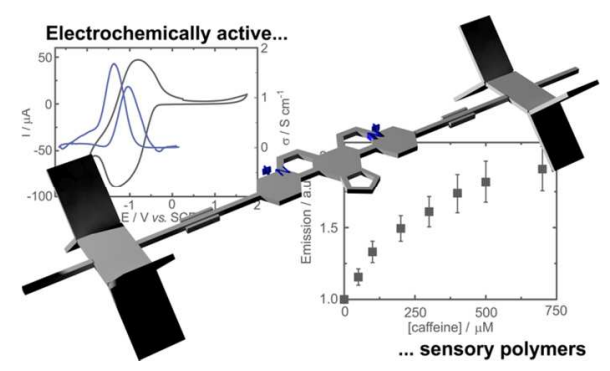

